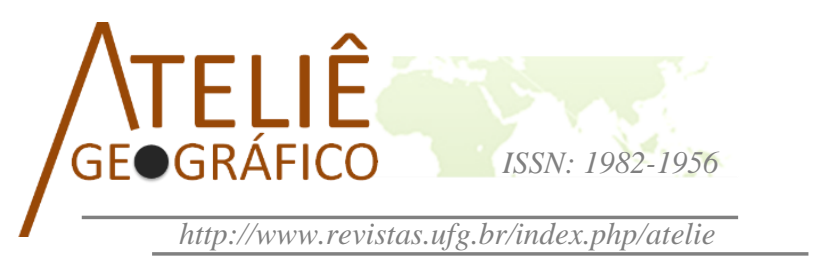

\title{
Agronegócio e ambiente no Cerrado tocantinense: um panorama dos municípios com base em indicadores
}

\author{
Agribusiness and environment in the savannah of Tocantins \\ state, Brazil: an overview of municipalities based on \\ indicators
}

Agronegocio y ambiente en el Cerrado tocantinense: un panorama de los municipios con base en los indicadores

\author{
Lucas Barbosa e Souza \\ Universidade Federal do Tocantins \\ lbsgeo@uft.edu.br \\ Juliana Ramalho Barros \\ Universidade Federal de Goiás \\ juliana.ufg@superig.com.br
}

\begin{abstract}
Resumo
A recente expansão do agronegócio sobre o Cerrado tocantinense tem sido responsável por diferentes tipos de transformações nesse bioma-território, incluindo mudanças ambientais. Suas consequências podem afetar o clima, a água, a sociobiodiversidade e os modos de vida de populações, sobretudo daquelas que habitam o campo e que dependem diretamente da natureza para a sua autossustentação. Partindo desse contexto, o presente artigo tem como objetivo traçar um panorama da situação dos municípios do estado do Tocantins com base em diferentes indicadores: agropecuários (tais como áreas de cultivo, de pastagens e rebanhos) e ambientais (tais como desmatamento acumulado e déficits de reserva legal e de áreas de proteção permanente). Foi verificada também, dentro dos limites de cada município, a presença de comunidades tradicionais e de assentados rurais, grupos considerados mais expostos e vulneráveis às consequências negativas do agronegócio sobre o ambiente. Buscou-se, assim, conhecer a conjuntura do tema em escala estadual e identificar municípios prioritários para a realização de estudos detalhados e para a execução de políticas públicas de monitoramento, fiscalização e conservação ambiental.
\end{abstract}

Palavras-chave: fronteira agrícola; mudanças ambientais; sociobiodiversidade; Tocantins. 


\begin{abstract}
The recent expansion of agribusiness in Tocantins state's savannah has brought several kinds of changes to this biome territory, among them environmental ones. Its consequences may affect the climate, water resources, socio-biodiversity, and people's ways of life, particularly those who live in the countryside and rely directly on nature to support themselves. Grounded on such a context, this paper offers an overview of the current scenario of municipalities in Tocantins state based on indicators concerning agriculture and cattle raising (e.g. planting/pasture areas and cattle) as well as the environment (e.g. accumulated deforestation and deficits of legal reserves and permanent protection areas). The study verified, within the limits of each municipality, the existence of traditional communities and rural settlements, groups regarded as more exposed and vulnerable to agribusiness' negative effects on the environment. This paper ultimately aims to learn more about the context surrounding this topic at state level and identify municipalities that demand priority in the production of in-depth studies and the enforcement of public policies for environmental monitoring, inspection, and conservation.
\end{abstract}

Keywords: agricultural frontier; environmental changes; socio-biodiversity; Tocantins state.

\begin{abstract}
Resumen
La reciente expansión del agronegocio sobre el Cerrado tocantinense ha sido responsable de diferentes tipos de transformaciones en ese bioma-territorio, incluyendo cambios ambientales. Sus consecuencias pueden afectar el clima, el agua, la sociobiodiversidad y los modos de vida de las poblaciones, sobre todo de aquellas que habitan en el campo y que dependen de la naturaleza para su sustento. Con base en este punto de partida, el presente artículo tiene como objetivo trazar un panorama de la situación de los municipios de Tocantins con base en diferentes indicadores: agropecuarios (tales como áreas de cultivo, pastos y rebaño) y ambientales (como deforestación, disminuciones de las reservas legales y de las áreas naturales protegidas permanentes). Fue analizado también, dentro de los límites de cada municipio, la presencia de comunidades tradicionales y de asentamientos rurales, grupos más expuestos y vulnerables a las consecuencias negativas del agronegocio sobre el ambiente. Se busca así, conocer la coyuntura del tema en escala estatal e identificar los municipios prioritarios para la realización de estudios detallados para la ejecución de políticas públicas de monitoreo, fiscalización y conservación ambiental.
\end{abstract}

Palabras clave: Frontera agrícola, câmbios ambientales, sociobiodiversidad, Tocantins.

\title{
Introdução
}

Uma conjuntura internacional propícia ao mercado de commodities agrícolas tem incentivado o agronegócio brasileiro a aprofundar sua territorialização no Cerrado ao longo das últimas décadas. A porção centro-norte do país, onde se localiza o estado do Tocantins, constitui uma área de expansão recente dessa fronteira agrícola, integrante da área designada como MATOPIBA (Maranhão, Tocantins, Piauí e Bahia), configurando-se gradualmente como uma região produtiva do agronegócio. Trata-se de uma área onde muitos esforços 
convergem para a consolidação do setor agropecuário, com investimentos e tecnologias voltados à alta produtividade (OLIVEIRA, 2015; ELIAS, 2015; EMBRAPA, 2014).

Nos planos político e ideológico, por sua vez, esse avanço tem sido respaldado pelo argumento de que o crescimento econômico e a modernização acelerada das atividades produtivas no campo são o caminho inequívoco para o desenvolvimento dos estados que se localizam em áreas de Cerrado, em cumprimento à sua aptidão "natural" para a produção de alimentos (CHAVEIRO; BARREIRA, 2010). Refere-se, nesse caso, ao desenvolvimento com viés economicista e retórico, forjado no âmbito moderno-colonial, ancorado na ideia de progresso material, pautado na exploração da natureza e pretensamente válido a todos os povos, tal como questionado por Porto-Gonçalves (2013).

Com base nesse modelo, tem-se observado no Tocantins a instalação de inúmeras corporações ligadas, direta ou indiretamente, ao agronegócio, que pouco a pouco contribuem para adaptar o espaço geográfico aos seus interesses de reprodução e acumulação de capital (LIMA, 2015), o que envolve, além de consequências sociais, repercussões ambientais.

Discursos quase sempre vazios voltados à questão da sustentabilidade (sem a explicitação de seus fundamentos) e da contribuição para a economia do estado (sem a apresentação de resultados concretos para a coletividade, como os de arrecadação, por exemplo), somam-se à omissão quanto às potenciais consequências negativas do agronegócio para o ambiente. Ainda que pese a exigência normativa para o licenciamento ambiental de atividades agropecuárias e afins (TOCANTINS, 2005), essas implicações do agronegócio merecem ser problematizadas, sobretudo em um contexto de protagonismo desse setor produtivo no cenário estadual. Somam-se a isso os limites impostos pelo caráter políticoinstitucional da regra estabelecida (construída em um ambiente político em que os interesses corporativos e de classe quase sempre prevalecem) e as dificuldades de dimensionamento dos efeitos cumulativos e emergentes relacionados ao conjunto das atividades licenciadas individualmente.

As transfigurações recentes observadas no Cerrado, frutos do conflito entre o modelo produtivo do agronegócio, a exploração da natureza e a qualidade ambiental, são apresentadas por Morais (2006), que ressalta a sustentação política desse processo. Para o autor, a revisão constitucional ocorrida em 1988 não possibilitou ao Cerrado os mesmos cuidados atribuídos a outros biomas brasileiros, como a Amazônia e a Mata Atlântica, tratouo como "bioma de $2^{a}$ classe" (MORAIS, 2006, p. 129). Chaveiro e Barreira (2010) mostram que tal concepção remonta às representações construídas pelos viajantes naturalistas que percorreram o Cerrado, então designado como "sertão", em especial no século XIX. Desde então, passando pelas diferentes iniciativas para a sua incorporação produtiva ao longo do século XX, tratou-se de estabelecer uma espécie de "função" para o Cerrado no plano nacional, culminando com sua atual situação de degradação.

Diferentes problemas induzidos ou agravados pelo agronegócio acometem o Cerrado, por conta da intensiva utilização de suas terras com finalidades de ganho privado e corporativo. A exploração da natureza para a produção nos moldes vigentes desse setor envolve, em primeiro lugar, modificações de superfície. No caso da soja, principal produto da 
agricultura tocantinense, Richards (2015) demonstrou que o cultivo exerce influência tanto direta quanto indireta sobre o desmatamento, afetando o preço da terra nas áreas de expansão e incentivando a supressão da vegetação em remanescentes florestais das propriedades, para a abertura de novas áreas. Tal processo, por sua vez, conduz às perdas de habitat, ao aprofundamento da fragmentação florestal, à diminuição da diversidade biológica, às mudanças na ciclagem da água e às perdas de solo (FEARNSIDE, 2006; CARVALHO; DE MARCO JÚNIOR; FERREIRA, 2009; FRANÇOSO et al., 2015).

Tais transformações superficiais são também capazes de alterar o clima, especialmente em suas escalas inferiores (local, topoclimática e microclimática), conforme bem explicado desde os trabalhos de Ribeiro (1993) e de Tarifa (1994). Sobre esse tema, Maitelli e Oliveira (2011) argumentam que a substituição da cobertura natural do solo (vegetação) por áreas de cultivo (lavouras e pastagens) causa mudanças no balanço de energia, isto é, nas trocas de radiação e calor entre a superfície e a atmosfera, por exemplo, pela redução do consumo de energia pelas plantas para a realização de trocas gasosas. Contribui-se, portanto, para aumentar a disponibilidade de calor sensível na baixa atmosfera, elevando a temperatura do ar.

Em relação à água, as mudanças de superfície e as atividades relacionadas ao avanço do agronegócio no Cerrado contribuem para o desequilíbrio entre as taxas de infiltração e de escoamento superficial (BALBINOT et al., 2008; MENDONÇA et al., 2009). De maneira ampliada, isso pode afetar a recarga dos aquíferos sob o Cerrado, assim como há tempos salientado por Ab'Sáber (2003), que mencionava, de modo especial, a situação das chapadas. Soma-se a isso o fato de o conjunto de atividades produtivas do agronegócio (agricultura irrigada, pecuária e processamento de matéria-prima pela agroindústria) demandar um volume vultoso de água, formando um quadro concomitante de redução da oferta e ampliação da demanda por recursos hídricos. Trata-se, pois, de uma conjuntura capaz de fomentar os conflitos por água envolvendo diferentes grupos sociais em desequilíbrio de forças políticas e econômicas, como explicado por Campos Filho (2010) e também reforçado por Elias (2015).

Por fim, não se podem esquecer as implicações do emprego em larga escala de produtos agrotóxicos no campo, prática estabelecida no âmbito da agricultura brasileira e cujos efeitos ambientais são quase sempre subestimados ou simplesmente pouco conhecidos (SOARES; PORTO, 2012). Pignati, Oliveira e Silva (2014) chamam atenção para a situação de o Brasil constituir o maior consumidor mundial de agrotóxicos, o que leva à poluição do ambiente e às intoxicações agudas e crônicas de trabalhadores e da população que vive no entorno das áreas de cultivo. Uma vez que o Cerrado concentra a produção brasileira de commodities agrícolas, acaba também por concentrar o consumo desses produtos altamente nocivos. No Tocantins, os dados sobre a venda de agrotóxicos no período de 2000 a 2014 mostram uma evolução superior a $1.000 \%$, passando de 555,16 para $6.073,36$ toneladas de ingredientes ativos comercializados (IBAMA, 2016).

Malheiros (2016) nos explica que a configuração atual da paisagem do Cerrado é o resultado de um longo e complexo processo de adaptação, transcorrido em uma escala temporal própria da natureza. Consequentemente, argumenta que "[...] qualquer condição que 
se aproxima ou ultrapasse os limites de tolerância constitui-se um fator limitante à sobrevivência e/ou adaptação de espécies vegetais e animais" (MALHEIROS, 2016, p. 125126).

Contudo, as espécies biológicas não são as únicas suscetíveis de sucumbir às mudanças ambientais impostas pela ação do capital. Considerando a ideia de (in)justiça ambiental, conforme definida por Acselrad, Mello e Bezerra (2009), deve-se atentar para o fato de que a parcela mais pobre da população é aquela mais comumente atingida pelos impactos ambientais de diferentes tipos de atividades produtivas. Nesse sentido, tomando o campo como o lócus das transformações ambientais promovidas diretamente pelo agronegócio, os grupos tradicionais e de camponeses que habitam esse espaço são os mais fortemente afetados por esse processo (MAZZETTO-SILVA, 2009).

Trata-se de populações cujos modos de vida dependem diretamente da natureza, compondo o que Diegues (2005) denomina de sociobiodiversidade, ou seja, a diversidade de saberes e de manifestações culturais que se funde à diversidade biológica em um modo de vida, em geral, de baixo impacto e, em muitos casos, de contornos contra hegemônicos. Para esses grupos, os problemas ambientais relacionados ao agronegócio podem interferir em inúmeros aspectos, como na alimentação, na saúde, no sustento, nos saberes e na cultura (MAZZETTO-SILVA, 2009).

Tomado por esse prisma, o Cerrado não pode ser tratado apenas em sua condição de bioma, mas também de território, o que permite incorporar aspectos de sua apropriação e significado por/para diferentes grupos sociais. Logo, a compreensão do Cerrado como um bioma-território, na concepção de Chaveiro e Barreira (2010) e de Castilho e Chaveiro (2010), possibilita operacionalizar uma abordagem condizente com tal complexidade, permitindo ultrapassar a produção de conhecimento, "[...] mas produzir sentido com o conhecimento" (CASTILHO; CHAVEIRO, 2010, p. 36).

Partindo desses pressupostos, o objetivo deste artigo é traçar um panorama a respeito das condições ambientais e das atividades típicas do agronegócio no Cerrado tocantinense, por meio de indicadores na escala municipal. Busca-se, por esse expediente, auxiliar na identificação de municípios prioritários para estudos detalhados e para aplicação de políticas públicas de monitoramento, fiscalização e conservação no cenário estadual.

A pesquisa foi realizada a partir de indicadores disponibilizados pelo portal eletrônico do Laboratório de Processamento de Imagens e Geoprocessamento (LAPIG) do Instituto de Estudos Socioambientais (IESA) da Universidade Federal de Goiás (UFG), por meio da ferramenta Inteligência Territorial. Dadas as mudanças ambientais em curso no estado do Tocantins, em virtude da pressão exercida pelo avanço da fronteira agrícola, o uso de indicadores pode constituir importante estratégia de avaliação e monitoramento, no sentido de guiar políticas públicas e atividades de fiscalização, entre outras finalidades. No sentido inverso, os indicadores também podem revelar o sucesso ou o fracasso de iniciativas tomadas pelos governos, prestando-se assim para avaliar as políticas desenvolvidas no plano ambiental (DAHL, 2012). O uso de indicadores é ponderado por Santos (2004), que apresenta uma extensa lista de critérios para dimensionar suas qualidades, entre eles a 
confiabilidade, a validade científica, a abrangência geográfica, a atualização dos dados, além de parâmetros como a acessibilidade e o custo para aquisição, aspectos satisfatoriamente atendidos pela fonte selecionada.

Já os indicadores escolhidos fazem referência a dois conjuntos de fatores, que se relacionam, respectivamente, ao estado e às pressões ambientais no âmbito de cada um dos 139 municípios tocantinenses, em números relativos (\%). O primeiro conjunto diz respeito ao desmatamento acumulado (2008 a 2015), à extensão territorial dos remanescentes de vegetação nativa e aos déficits de áreas de proteção (áreas de proteção permanente e reservas legais). O segundo grupo se refere à extensão das principais atividades agropecuárias desenvolvidas nos municípios, como a agricultura, a pecuária e a silvicultura. De modo complementar, procurou-se também verificar a presença de comunidades tradicionais (principais tipos presentes no Tocantins) e de assentamentos rurais em cada limite municipal, no sentido de agregar informações que, a nosso ver, poderão indicar maior ou menor presença de populações vulneráveis no campo. Para a obtenção dessas informações, além dos dados do próprio LAPIG, foram empregados dados da FUNAI (Fundação Nacional do Índio), da Fundação Palmares, do INCRA (Instituto Nacional de Colonização e Reforma Agrária), do MIQCB (Movimento Interestadual das Quebradeiras de Coco Babaçu) e da tese de Rocha (2011).

Um conjunto de indicadores dificilmente conseguirá reunir uma lista ideal de parâmetros para retratar um dado fenômeno em investigação. Contudo, a conjugação ora definida, além da pronta disponibilidade, possui a capacidade de evidenciar, direta ou indiretamente, importantes aspectos que envolvem o agronegócio, as condições ambientais e a pressão exercida sobre populações no Cerrado. Outra ressalva importante diz respeito à circunstância de que as dinâmicas próprias da natureza e a manifestação espacial dos problemas ambientais não se limitam às divisas administrativas dos municípios, difundindose pelas bacias hidrográficas e pela atmosfera, por exemplo. Nesse aspecto, a estrutura dos dados, correspondente à esfera municipal, constitui uma limitação que não pode ser desconsiderada no processo de análise e interpretação.

Por fim, para efeito didático-analítico, bem como para não trazer ao exame um volume exaustivo de informações, optou-se, neste artigo, pela apresentação dos resultados referentes aos dez principais municípios para cada indicador. Tal deliberação prestará, pois, para traçar o panorama almejado sobre a temática em território tocantinense, nos termos apresentados.

\section{Tendências relacionadas ao desmatamento e aos aspectos hidroclimáticos no Tocantins}

As pesquisas que abordam o processo de desmatamento do Cerrado têm demonstrado que se trata de um fenômeno com significativa mobilidade, influenciado por diferentes variáveis, como o preço da terra, o preço das commodities agrícolas no mercado internacional, os incentivos públicos, a ação de grandes corporações ligadas ao agronegócio, a infraestrutura logística, entre outras (SALMONA, 2013). Em estudos focados na década de 2000, Silva e Anjos (2010) e Rocha et al. (2011) indicaram que uma das principais frentes de 
desmatamento do Cerrado já estava localizada em bacias hidrográficas ou em municípios pertencentes ao domínio do MATOPIBA, justamente em áreas até então com maiores extensões de remanescentes de vegetação nativa nesse bioma-território. Para as próximas décadas, os cenários obtidos por modelagem indicam a manutenção de remanescentes do Cerrado praticamente restrita às áreas indígenas, às unidades de conservação e às áreas residuais com maiores declividades, onde a agricultura mecanizada encontra restrições para operar (SALMONA, 2013).

Especificamente no território tocantinense, por integrar a Amazônia Legal, as áreas desmatadas a corte raso (a partir de 6,25 hectares) são monitoradas pelo Projeto PRODES (Monitoramento do Desmatamento na Amazônia Legal por Satélite). Os dados mostram uma redução gradativa das áreas desmatadas desde 1988, quando se iniciou o acompanhamento. No entanto, a supressão da vegetação prossegue ativa no estado, mantendo números anuais de dezenas de quilômetros quadrados. A área desmatada em 2016 chegou a um valor de 80 $\mathrm{km}^{2}$, apresentando um aumento de cerca de $40 \%$ em relação ao ano anterior $\left(57 \mathrm{~km}^{2}\right)$ e atingindo um valor acumulado (1988 a 2016) de $8.644 \mathrm{~km}^{2}$ (INPE, 2017).

Já os dados disponíveis no Portal do LAPIG (IESA/UFG) apontam para um desmatamento acumulado de 652.143 hectares no estado do Tocantins, referente ao período de 2008 a 2015. Por sua vez, os déficits mensurados de reserva legal (RL) e de área de proteção permanente (APP) são, respectivamente, de 698.159 hectares e de 123.581 hectares, o que indica o descumprimento de exigências legais por parte de proprietários fundiários, além da possibilidade de problemas ambientais decorrentes das alterações na cobertura natural do solo.

Nesse sentido, estudos também têm indicado tendências de aquecimento de superfícies e do ar atmosférico sobre o Tocantins. Com o auxílio de imagens térmicas orbitais, Santos (2010) verificou as temperaturas superficiais no Cerrado, entre os anos de 2003 e 2008, observando que as áreas de uso agropecuário no Tocantins destacavam-se pela maior frequência de pontos de aquecimento. Com o uso da mesma técnica, Pires e Ferreira (2014) avaliaram as temperaturas superficiais nos municípios de Palmas e de Porto Nacional, nos arredores do reservatório da UHE Luís Eduardo Magalhães, em diferentes momentos (anos de 2001, 2006 e 2011). Os autores perceberam tendência de aquecimento das superfícies ao longo do período analisado, com destaque para áreas de uso agrícola e com solo exposto (como áreas de lavoura em intervalos entre plantios).

Já por meio do exame de dados climatológicos e da aplicação de testes estatísticos não paramétricos, dois trabalhos recentes merecem destaque: Almeida et al. (2016) e Penereiro, Martins e Beretta (2016). Almeida et al. (2016) enfocaram o período de 1973 a 2013, por meio de dados da rede de observação do Instituto Nacional de Meteorologia (INMET). Selecionaram estações instaladas em território da Amazônia Legal, incluindo estações no Tocantins e no entorno imediato do estado. Os dados mostraram tendência de elevação das temperaturas mínimas, médias e máximas no intervalo analisado, com destaque para as estações de Porto Nacional, Peixe e Pedro Afonso, municípios tocantinenses com expressivo avanço do agronegócio. 
Penereiro, Martins e Beretta (2016) realizaram estudo semelhante com dados do Instituto Nacional de Meteorologia (INMET) e da Agência Nacional das Águas (ANA). Enfocaram o comportamento da temperatura do ar, das precipitações e das vazões na bacia do Tocantins-Araguaia ao longo das últimas décadas (em intervalo não padronizado). Em termos de temperatura do ar, os autores detectaram tendências claras de elevação das temperaturas mínimas (em Araguaína, Palmas, Peixe e Pedro Afonso), das temperaturas máximas (em Araguaína, Palmas, Porto Nacional e Taguatinga) e das temperaturas médias (em Araguaína e Palmas). Quanto à precipitação pluvial, não foi observada nenhuma tendência clara, o que indica que os volumes precipitados se encontram em relativa estabilidade. Porém, contraditoriamente às precipitações, os dados hidrológicos inspecionados apontam tendência de decréscimo das vazões no caso específico do rio Tocantins, o que pode estar relacionado, entre outros fatores, às mudanças de superfície e dos fluxos hidrológicos que alimentam os cursos d'água na bacia.

As diferentes pesquisas envolvendo aspectos hidroclimáticos no Tocantins mostram que as tendências dos dados variam em magnitude entre as estações selecionadas, reforçando a ideia de que as alterações atingem especialmente o clima em sua escala local. Soma-se a isso o fato de que as mudanças de superfície, iniciadas com a retirada da vegetação do Cerrado, dependem de uma série de fatores que variam entre as localidades e seus atributos, conforme já apontado. Logo, amplia-se o interesse por um exame mais pormenorizado do cenário em nível municipal, assunto que será tratado a seguir.

\section{Indicadores ambientais e agropecuários: municípios prioritários no Cerrado tocantinense}

Como anteriormente explicado, os resultados que seguem estão baseados nos dez principais municípios segundo cada indicador analisado, o que nos permite chamar a atenção para as situações mais preocupantes no território em análise. As Figuras 1 e 2 apresentam, respectivamente, os maiores percentuais de desmatamento acumulado (relativo à área de cada município), no período de 2008 a 2015, e os menores percentuais de remanescentes de vegetação nativa, referentes ao ano de 2012.

Os municípios com expressiva produção agrícola recente, especialmente de soja, se destacam quanto ao desmatamento acumulado nos últimos anos (Santa Rosa do Tocantins, Caseara, Rio dos Bois, Silvanópolis, Peixe, São Valério da Natividade, Brejinho de Nazaré, Tupiratins e Pedro Afonso). Apenas o município de Cristalândia possui produção de soja menos expressiva, em detrimento da pecuária. A maior concentração desses municípios ocorre na porção centro-sul do estado (cinco municípios) e na bacia do Tocantins (oito municípios). É justamente nessa bacia onde foram averiguadas tendências de redução das vazões, segundo o trabalho de Penereiro, Martins e Beretta (2016). Cabe ressaltar que há comunidades tradicionais em pelo menos três municípios da lista: quilombolas em Santa Rosa do Tocantins e em Brejinho de Nazaré; e indígenas (Xerente) em Pedro Afonso. Quanto aos assentamentos rurais, há um total de 27 no conjunto dos municípios destacados na Figura 1, o que indica a 
presença de camponeses, cuja dependência da natureza está relacionada a modos menos intensivos e a escalas mais reduzidas de produção, em comparação com o agronegócio.

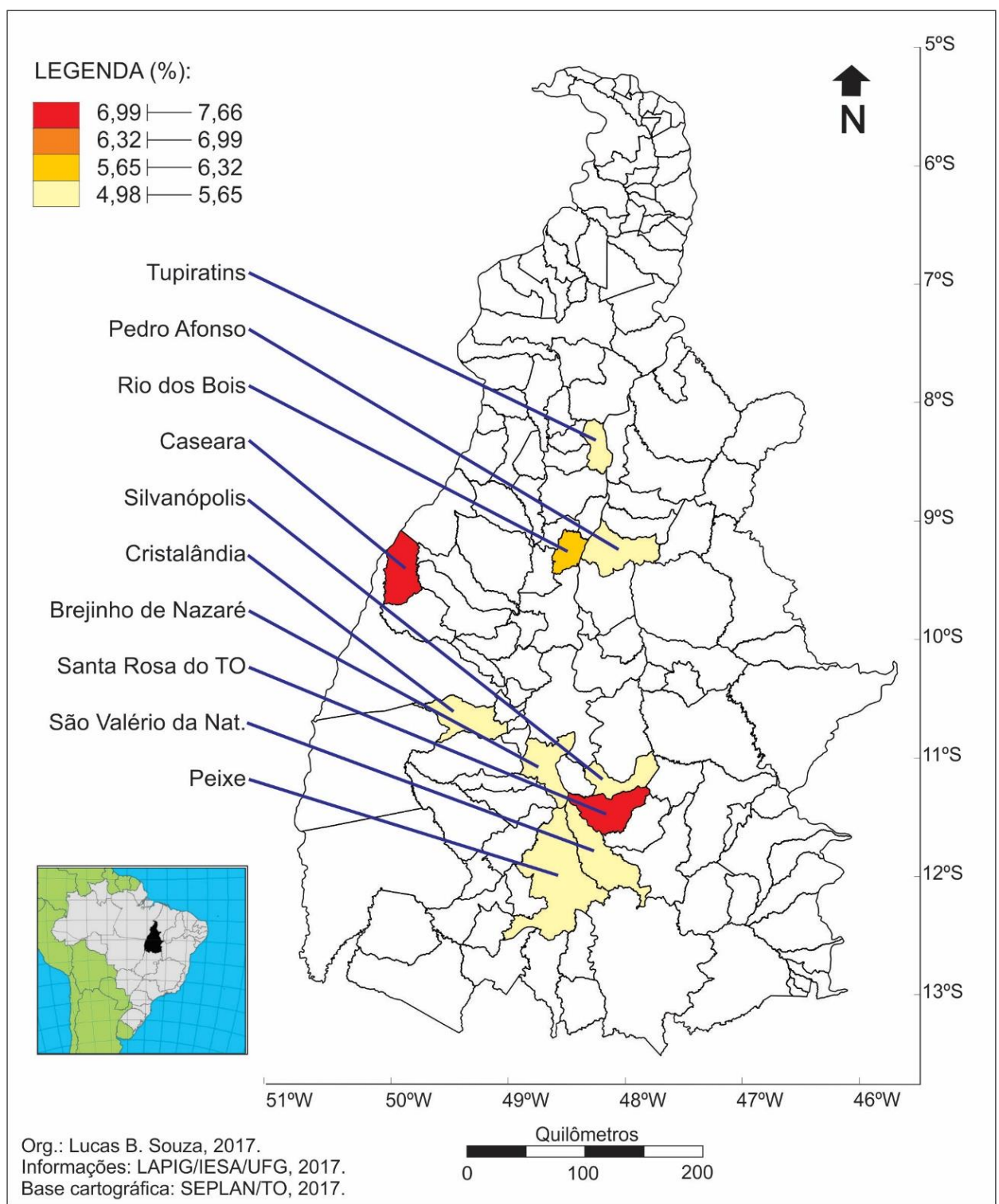

Figura 1: Maiores percentuais de desmatamento acumulado por área do município (2008/2015). 


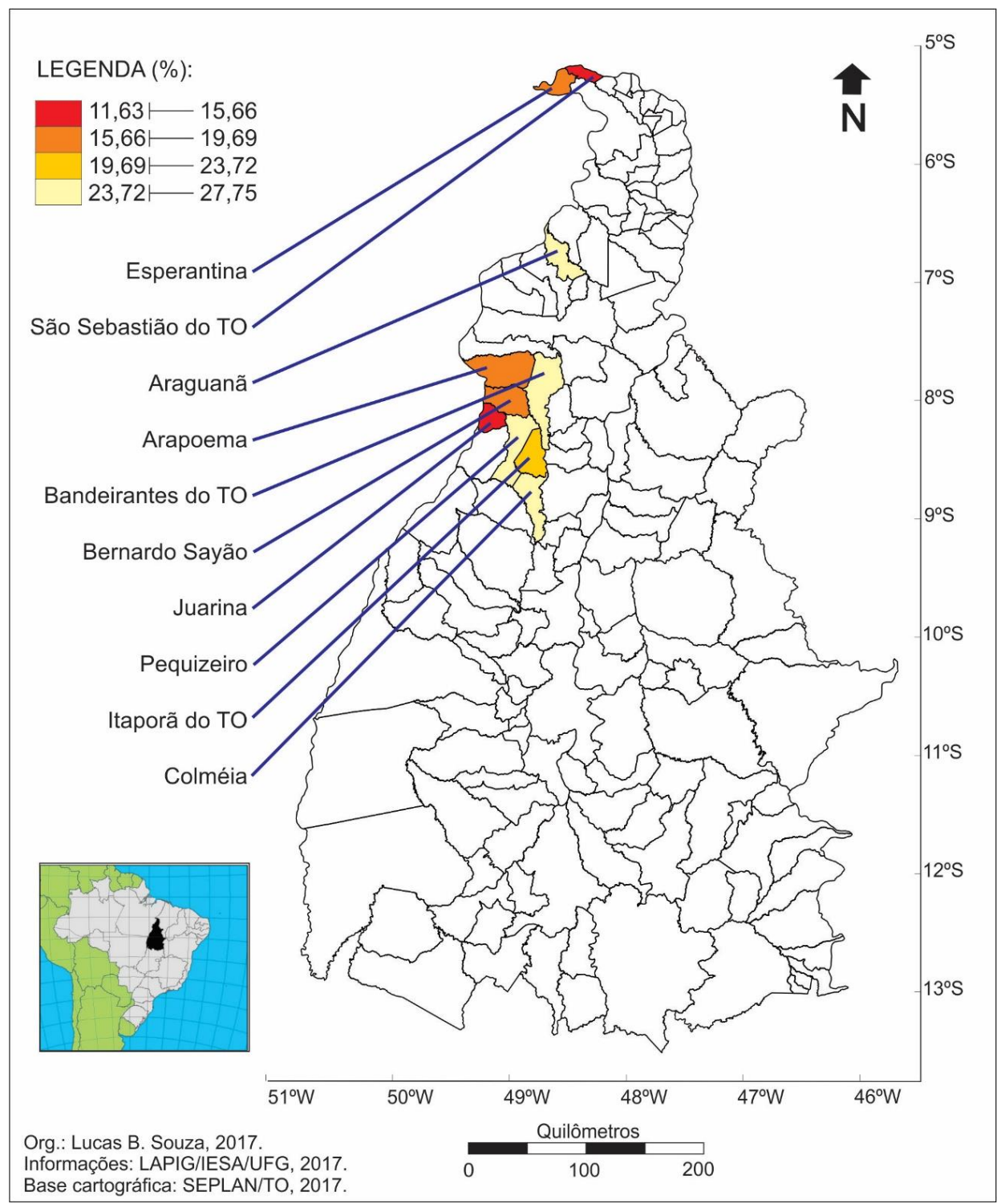

Figura 2: Menores percentuais de vegetação nativa por área do município (2012).

Na lista dos dez menores percentuais de remanescentes de vegetação nativa, todos os municípios integrantes são da porção norte do Tocantins, onde se destaca a atividade da pecuária extensiva de corte e, consequentemente, a presença de pastagens. Trata-se de uma área de transição entre o Cerrado e a Amazônia, com marcante presença dos babaçuais. A supressão da vegetação nativa pode afetar a manutenção de populações 
de quebradeiras de coco, presentes nessa região do estado (principalmente nos municípios de São Sebastião do Tocantins e de Esperantina), cujo sustento depende diretamente do babaçu. Existem 39 assentamentos rurais no conjunto desses municípios retratados na Figura 2. Como esses municípios não figuram na lista de desmatamento acumulado (2008-2015), é provável que a supressão da vegetação nativa tenha ocorrido em períodos anteriores, uma vez que a atividade da pecuária na região remonta há muitas décadas. Por isso, mesmo possuindo os menores remanescentes de vegetação nativa, os maiores percentuais de desmatamento no período analisado não ocorreram ali.

Os municípios localizados no Jalapão, na porção leste do estado, embora não figurem nas listas dos principais municípios em desmatamento acumulado e com os menores percentuais de vegetação nativa, devem ser alvo de preocupação por conta da pressão proveniente do desmatamento recente em áreas limítrofes na Bahia, no Piauí e no Maranhão (ROCHA et al., 2011), onde há forte presença e avanço do agronegócio.

As Figuras 3 e 4, a seguir, apontam a representação dos déficits municipais relativos de áreas de proteção permanente (APP) e de reserva legal (RL). Alguns também estão entre os que apresentam os menores percentuais de vegetação nativa (Figura 2), caso de Araguanã, Arapoema, Bernardo Sayão, Bandeirantes do Tocantins e Itaporã do Tocantins.

A maioria dos municípios que figuram entre os maiores déficits de áreas de proteção permanente também se localiza no norte do estado. No município de Santa Fé do Araguaia, que apresenta elevado déficit de reserva legal, encontram-se pelo menos três grupos de comunidades tradicionais: indígenas (Apinajé e Karajá) e quilombolas. Porém, em quatro municípios da porção sul do Tocantins (Sucupira, Talismã, Peixe e Araguaçu), a sojicultura é a principal atividade produtiva no campo. Em relação aos assentamentos rurais, há um total de 34 no conjunto de municípios destacados na Figura 3.

Quanto às áreas com déficit de reserva legal, todos os dez municípios são da região norte do estado e encontra-se ali um total de 27 assentamentos rurais instalados nas localidades destacadas na Figura 4. 


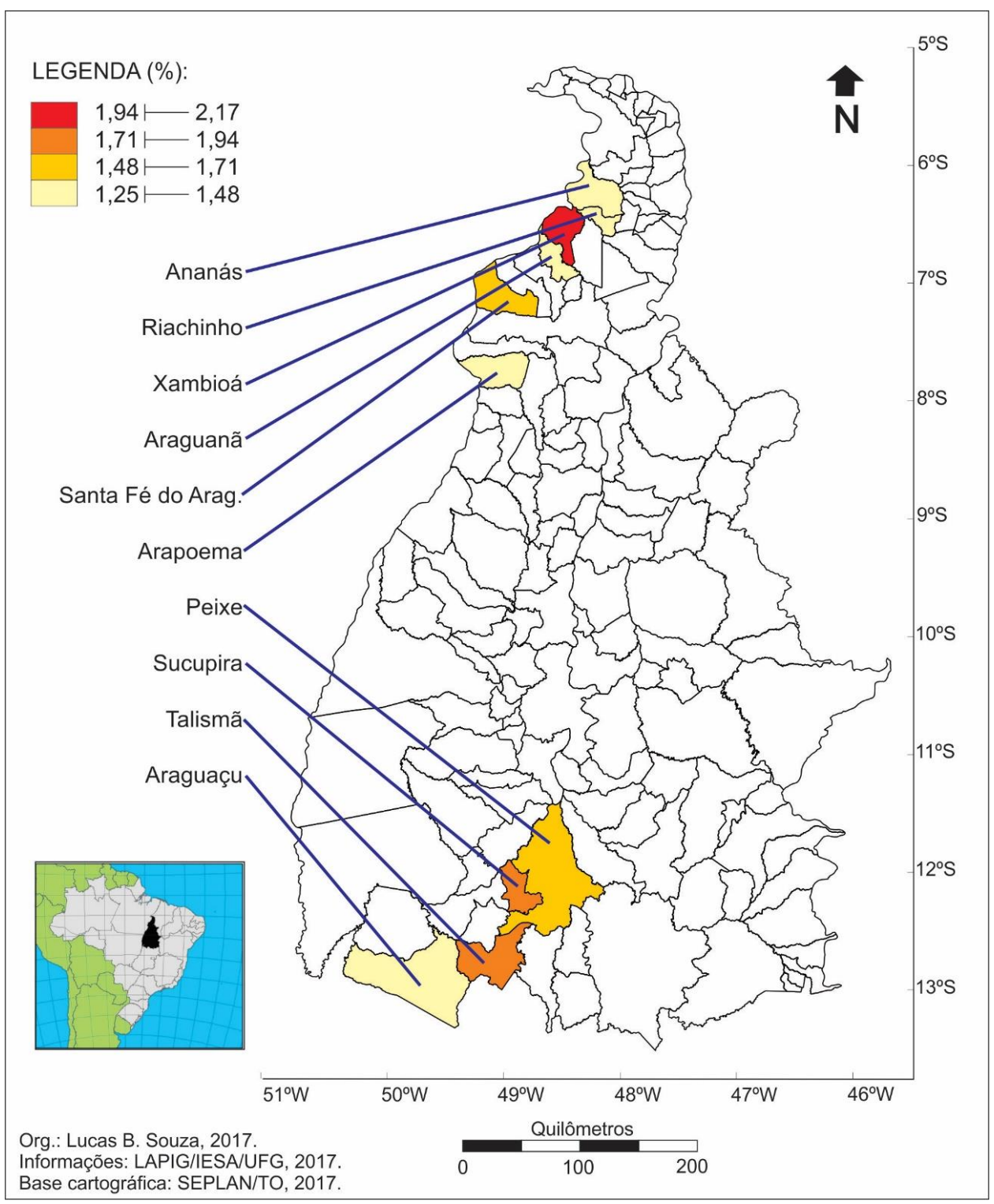

Figura 3: Maiores déficits de áreas de proteção permanente (APP) por área do município (2014). 


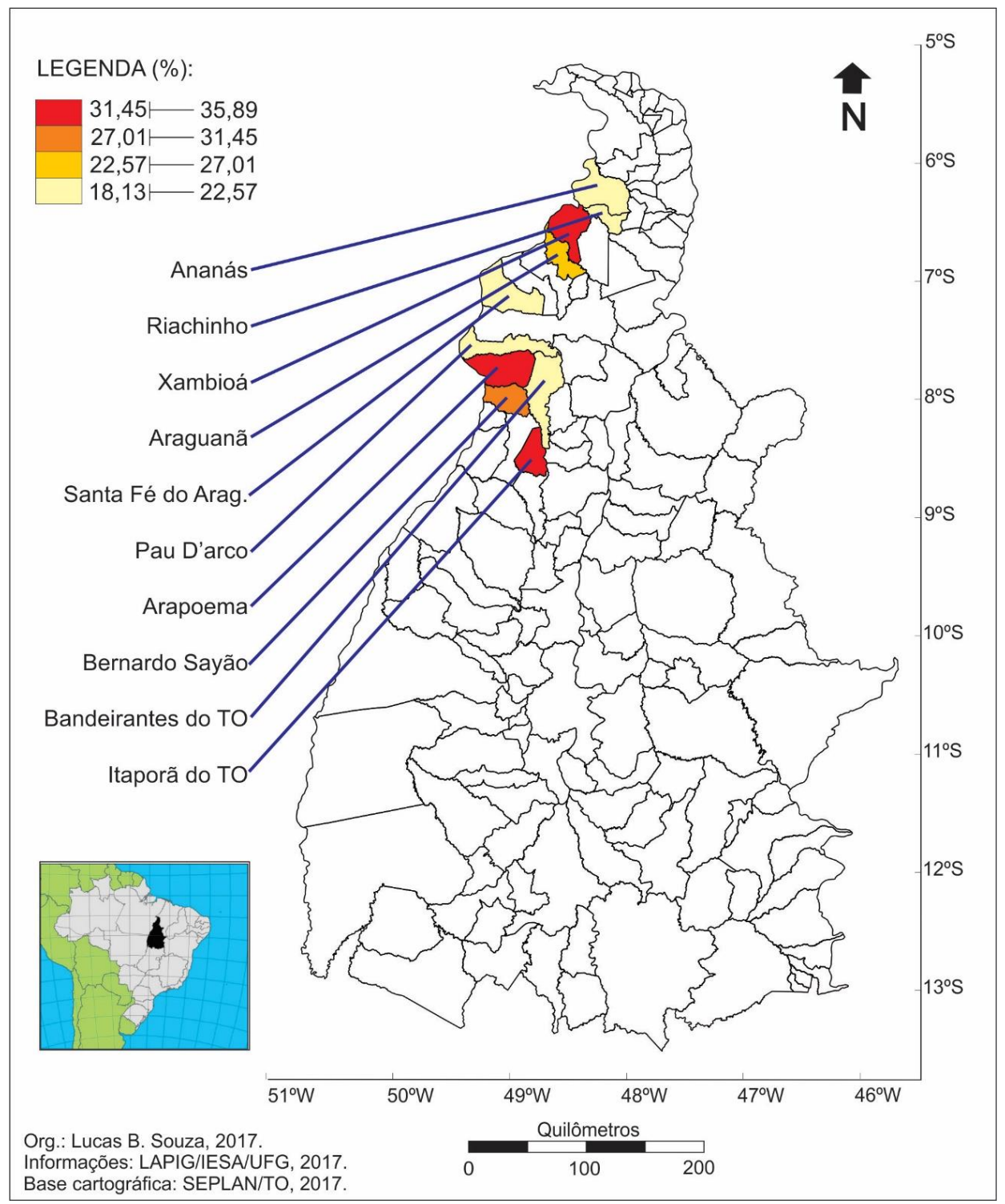

Figura 4: Maiores déficits de reservas legais (RL) por área do município (2014).

$\mathrm{Na}$ sequência, os maiores percentuais de áreas com cultivo agrícola (soja, milho, algodão e cana) e os maiores percentuais de áreas com silvicultura por município estão demonstrados nas Figuras 5 e 6, respectivamente. Cabe destacar que se um município apresenta números expressivos quanto às áreas utilizadas pela agricultura e pela silvicultura, isso não implica, necessariamente, na ocorrência de maiores problemas 
ambientais. Contudo, os resultados demonstram sobreposições de indicadores que merecem ser ressaltadas.

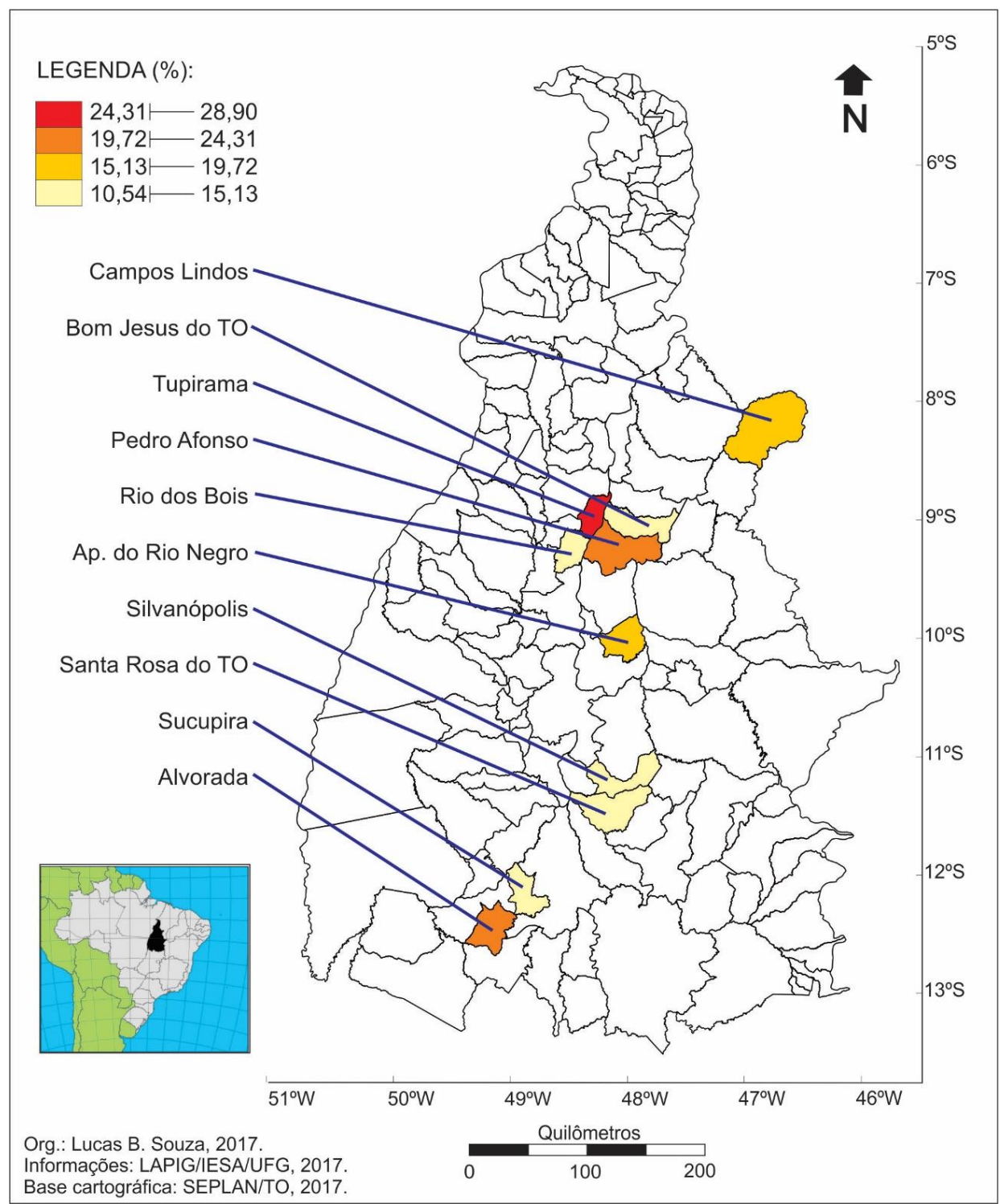

Figura 5. Maiores percentuais de áreas cultivadas (soja, milho, algodão e cana) por município (2014). 


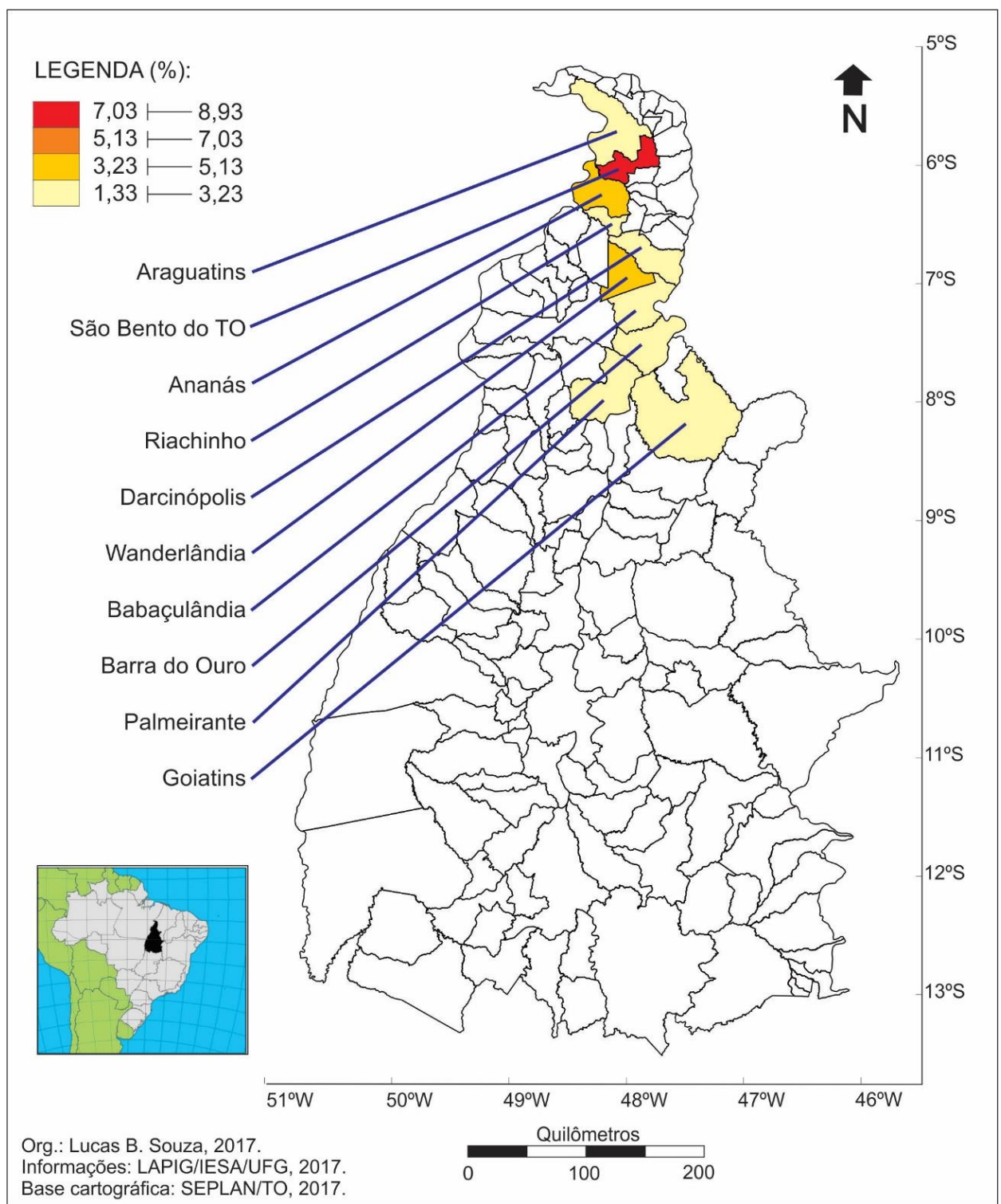

Figura 6: Maiores percentuais de áreas com silvicultura por município (2014).

Trata-se de sobreposições dos indicadores produtivos àqueles relacionados a problemas ambientais e ao descumprimento da legislação nesse campo: Pedro Afonso, Rio dos Bois, Silvanópolis e Santa Rosa do Tocantins estão entre os municípios com os mais altos percentuais de áreas cultivadas e também entre aqueles com os mais altos 
percentuais de desmatamento acumulado; Sucupira também está entre os municípios com alto percentual de área cultivada, ao passo que figura entre os maiores déficits de áreas de proteção permanente (APP).

A soja destaca-se pelas maiores áreas de cultivo em 82 municípios tocantinenses. Já o milho ocupa a maior área de cultivo em outros 55 municípios, porém, com extensões bastante inferiores aos da soja, em geral na casa de centenas de hectares somente. O cultivo da soja tem sido, desse modo, a principal atividade produtiva em termos de agricultura no estado do Tocantins, enquanto o milho permanece em uma posição secundária, sendo cultivado sob a forma de safrinha (juntamente com o sorgo e o milheto), a depender das condições pluviométricas, ou como principal cultivo, porém em áreas menores.

Assim, em relação aos dez maiores percentuais de área com cultivo agrícola no Tocantins, destacam-se os municípios com significativo percentual da área utilizado para cultivo da soja, com exceção de Pedro Afonso, onde a cana divide o espaço com a soja. Todos os municípios da lista encontram-se na bacia do Tocantins. Há concentração desses municípios em duas áreas diferentes: na porção centro-norte do estado (Tupirama, Pedro Afonso, Rio dos Bois e Bom Jesus do Tocantins), nas proximidades de áreas indígenas Xerente e Kraô; e na porção sul do estado (Santa Rosa do Tocantins, Alvorada, Silvanópolis e Sucupira). Há presença de quilombolas na primeira.

Existem apenas cinco assentamentos rurais no conjunto desses municípios, entre outros fatores, possivelmente pelo fato de haver maior número de propriedades consideradas produtivas, segundo o critério vigente brasileiro, o que dificulta a desapropriação da terra para efeito de reforma agrária.

Já quando a atividade é a silvicultura, os percentuais utilizados são bem menores, em comparação com as culturas temporárias. Os números mostram que tal atividade, ainda que em crescimento no estado, não possui expressividade até o momento. Percebe-se que os municípios da lista encontram-se na proximidade de potenciais compradores, especialmente de eucalipto, nos estados do Maranhão e do Pará. No primeiro, há a presença de uma unidade fabril de papel e celulose, em Imperatriz (MA). Já no segundo, há siderúrgicas (consumidoras de carvão vegetal) e também unidades produtoras de painéis de madeira.

Ananás e Riachinho estão entre os municípios com os mais altos percentuais de áreas com silvicultura e, ao mesmo tempo, figuram entre os maiores déficits de reserva legal (RL) e de áreas de proteção permanente (APP). Nos municípios destacados na Figura 6, encontram-se populações tradicionais, como indígenas Apinajé e Kraô, respectivamente, em São Bento do Tocantins e em Goiatins, além de quilombolas em Araguatins. Existem ainda 51 assentamentos rurais no conjunto dos dez municípios, sendo 21 somente no município de Araguatins, que é o principal do estado em número de assentamentos. Conforme já salientado, sabe-se que comunidades tradicionais e assentados rurais dedicam-se a atividades que promovem menos mudanças sob o ponto de vista ambiental, se comparadas com aquelas promovidas pela pecuária e pelas 
monoculturas comerciais de larga escala. No entanto, tais mudanças afetam diretamente esses grupos que dependem da natureza para a sua autossustentação.

Por fim, as Figuras 7 e 8 mostram dados referentes à atividade da pecuária bovina no Tocantins, com os maiores percentuais de pastagens por município e os maiores rebanhos bovinos por município, respectivamente. Durante muito tempo, essa foi a atividade dominante no estado e, atualmente, ainda é bastante forte.

Quanto aos maiores percentuais de áreas de pastagem, todos os municípios da lista também estão no norte do Tocantins, onde a pecuária se destaca como atividade no campo. Araguanã e Arapoema estão também entre os municípios com menores percentuais de áreas com vegetação nativa, maiores déficits de áreas de proteção permanente (APP) e de reserva legal (RL). Já Bernardo Sayão, Bandeirantes do Tocantins e Itaporã do Tocantins aparecem entre os municípios com menores percentuais de áreas com vegetação nativa e com os maiores déficits de reserva legal (RL).

Há presença de comunidades organizadas de quebradeiras de coco em pelo menos três municípios (Augustinópolis, Axixá do Tocantins e Sítio Novo do Tocantins), mas é provável que haja grupos isolados em outros municípios da lista. Além desses grupos, existem 30 assentamentos rurais no conjunto dos municípios. As pastagens detectadas pelo LAPIG dizem respeito às áreas pastoreáveis, não necessariamente a pastos cultivados. O fato de os municípios do norte do estado apresentarem, de forma geral, menor extensão territorial pode ser o motivo pelo qual os maiores rebanhos bovinos não se encontram localizados nessa área, onde também se disseminam os babaçuais. Nesse caso, podem existir conflitos territoriais entre pecuaristas e quebradeiras de coco. 


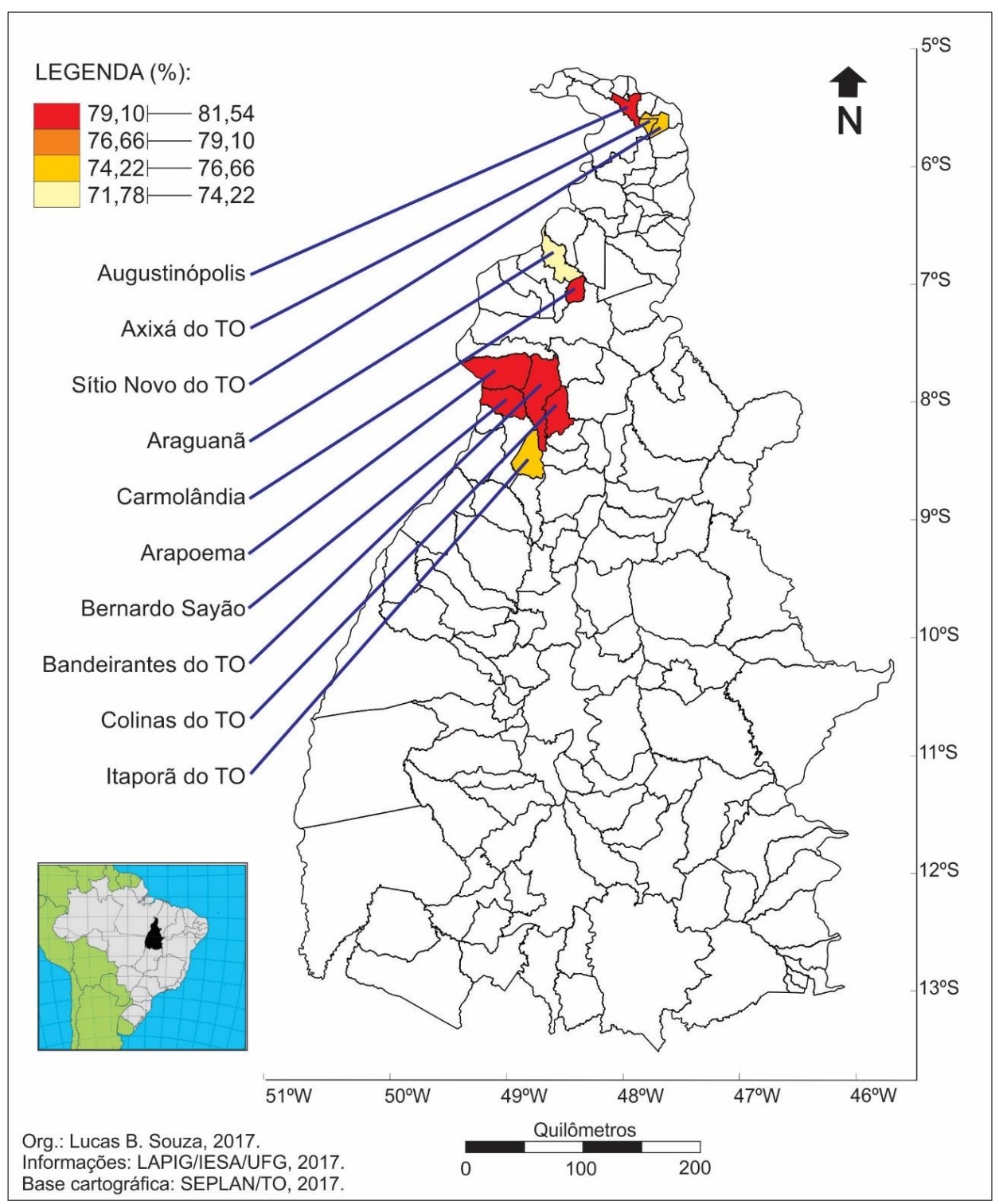

Figura 7: Maiores percentuais de áreas de pastagem por município (2015). 


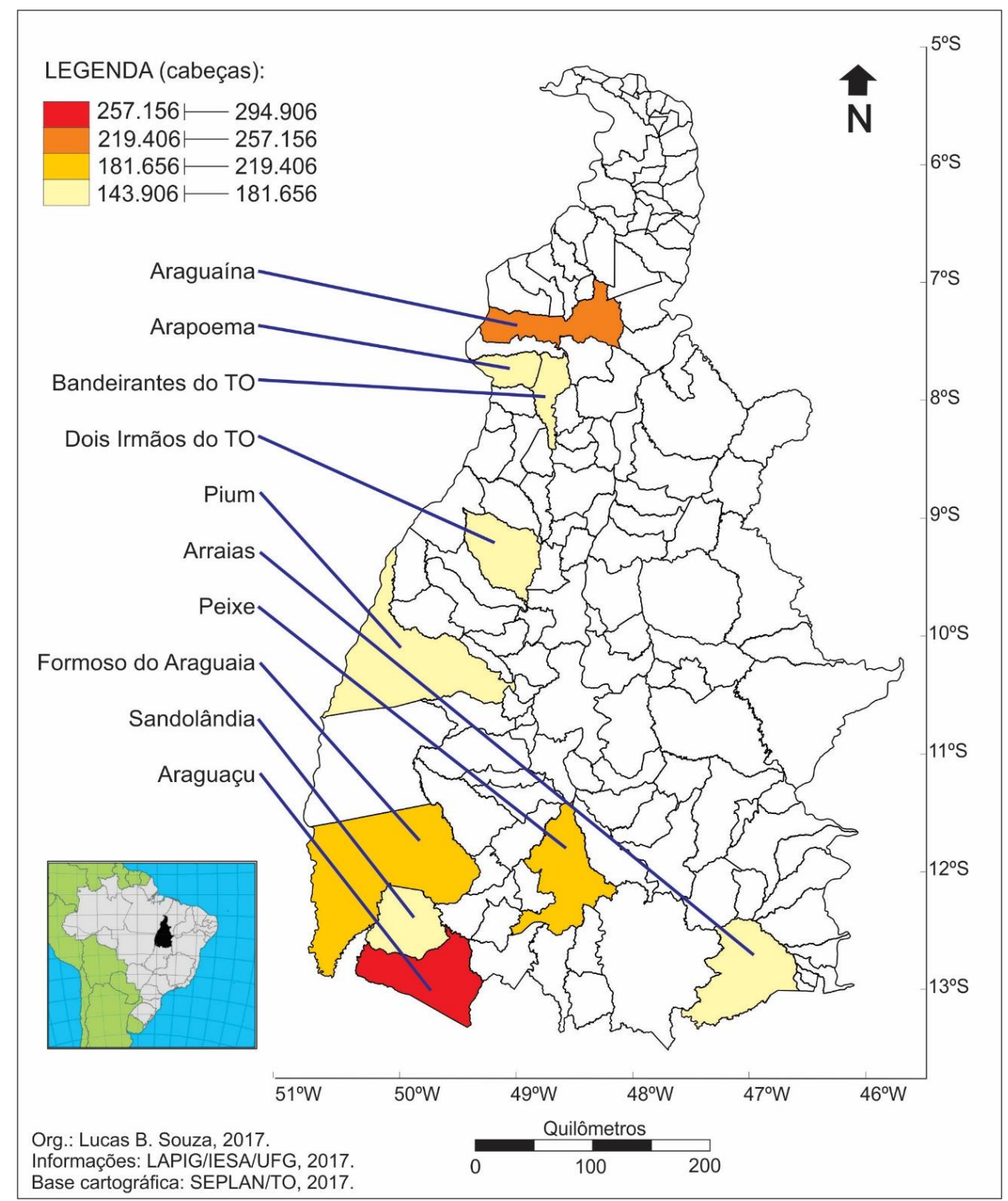

Figura 8: Maiores rebanhos bovinos por município (2014).

Entre os maiores rebanhos bovinos do Tocantins, destacam-se os municípios localizados na bacia do Araguaia (Araguaçu, Araguaína, Formoso do Araguaia, Pium, Bandeirantes do Tocantins, Sandolândia, Arapoema e Dois Irmãos do Tocantins), em especial aqueles com maior território municipal e área absoluta de pastagem. Existem grupos de comunidades tradicionais em metade dos municípios da lista: indígenas em 
Formoso do Araguaia, Pium e Sandolândia (Javaé, Karajá, Avá-Canoeiro e Tapirapé) e quilombolas em Arraias e Dois Irmãos do Tocantins, além de 39 assentamentos rurais no conjunto dos 10 municípios da lista. Certamente pode haver rebanhos próprios dessas comunidades, porém o quantitativo mais expressivo está vinculado aos grandes latifúndios, comuns nesses municípios.

Da lista de maiores rebanhos bovinos, somente Peixe aparece na lista de desmatamento acumulado (2008-2015), o que pode indicar que o desmatamento para implantação de pastagens nessas localidades (exceto em campos inundáveis ou várzeas das planícies do Araguaia) deve ter ocorrido em períodos anteriores ao monitoramento pelo LAPIG (antes de 2008). Na lista com os menores percentuais de áreas com vegetação nativa e na lista com os maiores déficits de reserva legal (RL), constam os municípios de Arapoema e Bandeirantes do Tocantins, enquanto na lista com os maiores déficits de áreas de proteção permanente (APP), aparecem Arapoema, Araguaçu e Peixe. Tais sobreposições indicam, nesses casos, a possibilidade de vínculos entre a pecuária e a ocorrência de problemas relacionados à supressão da vegetação.

\section{Considerações finais}

O estado do Tocantins sempre apresentou forte presença da pecuária bovina extensiva, atividade que, durante muito tempo, teve predomínio e ainda hoje se mostra bastante vigorosa. Contudo, não se pode dissociar a dinâmica do uso e da ocupação de suas terras daquela ocorrida no restante do Cerrado brasileiro.

Nesse sentido, destaca-se o papel de algumas iniciativas, a exemplo do Programa de Desenvolvimento dos Cerrados (POLOCENTRO) e de pesquisas realizadas pela Empresa Brasileira de Pesquisa Agropecuária (EMBRAPA). Seus esforços se voltaram, a partir da década de 1970, para a incorporação produtiva desse bioma a outras áreas do território nacional. Na década de 1980, a partir da interiorização e do fortalecimento da pesquisa para o setor agrícola no país, assim como os investimentos em infraestrutura a fim de aumentar a produção e propiciar as condições para o armazenamento e o escoamento dos produtos, observou-se a expressiva ampliação da fronteira agrícola no Brasil.

À medida que as inovações tecnológicas e as políticas de Estado propiciaram o crescimento da agricultura no Cerrado, com destaque para o cultivo de grãos, o estado do Tocantins, criado pela Constituição Federal de 1988, passou a atrair, gradativamente, essa atividade, especialmente o plantio de soja. Pode-se atribuir isso à grande quantidade de terras com topografia favorável às práticas mecanizadas, à correção da fertilidade dos solos, às novas sementes adaptadas e ao menor valor das terras em comparação com áreas nas quais o agronegócio já estava consolidado há mais tempo, a exemplo dos estados de Goiás e Mato Grosso. Somam-se a isso as melhorias logísticas que ocorreram a partir da última década, como a construção de silos para estocagem, início da instalação de estrutura portuária fluvial e a construção da ferrovia Norte-Sul, além de uma configuração favorável no mercado internacional para a soja e a chegada, em terras 
tocantinenses, de diferentes corporações nacionais e multinacionais exportadoras. Tudo isso favoreceu o avanço da produção e, consequentemente, o crescimento do agronegócio em diversos municípios do Tocantins.

Todavia, isso acaba por gerar um passivo ambiental, principalmente em razão do desmatamento, da utilização dos recursos hídricos e do emprego de agrotóxicos, o que atinge mais diretamente as comunidades que vivem no campo. Nas localidades onde a pecuária extensiva ainda se mantém forte, especialmente no norte do estado, observam-se os maiores problemas relacionados ao descumprimento da legislação ambiental, já que essa atividade é desenvolvida sobre bases produtivas, em geral, ultrapassadas.

Nos municípios cuja principal atividade é o cultivo de grãos, com destaque para a soja, parece haver maior preocupação com a adequação às leis vigentes. Contudo, isso não evita que grandes áreas sejam desmatadas, mesmo em conformidade com a lei, e que as mudanças no uso e na cobertura do solo resultem em consequências como perda de biodiversidade, degradação dos solos e poluição de cursos d'água. Além disso, o modelo adotado faz com que a agricultura demande grande quantidade de água, devido à necessidade de irrigação, tendendo a agravar as pressões sobre o meio ambiente e as disputas por esse recurso, que tem se tornado escasso.

A silvicultura, que ainda não ocupa uma posição muito expressiva na economia do estado, concentra-se em municípios da porção norte, provavelmente em razão da proximidade com os estados do Maranhão e do Pará, que são importantes mercados compradores dos produtos do setor. Porém, essa atividade produtiva vem apresentando crescimento nos últimos anos, além de uma organização política mais expressiva, por meio de uma associação estadual. A tendência, nesse caso, é adquirir maior importância no futuro próximo, e suas consequências ambientais devem ser acompanhadas com o tempo.

O agronegócio vem se fortalecendo como a principal atividade econômica no estado do Tocantins, e esse movimento tem atraído um número crescente de produtores e empresas que, em geral, já possuem experiência em outras áreas, como Goiás, Mato Grosso, oeste da Bahia e sul/sudoeste do Piauí. Contudo, é preciso atentar para as especificidades regionais internas e pensar em um modelo que seja mais adequado, visto que as implicações ambientais do agronegócio adotado em outros estados vêm se mostrando perigosas e injustas.

A histórica ausência estatal e de serviços públicos no âmbito do Tocantins, principal argumento para a sua emancipação em 1988, parece repercutir ainda hoje em graves deficiências no monitoramento ambiental por parte dos órgãos responsáveis, o que facilita práticas ilícitas, como o desmatamento ilegal e o uso indevido dos recursos hídricos, assim como o consequente surgimento de conflitos entre grandes produtores rurais e comunidades que vivem no campo. Do mesmo modo, a interferência política direta sobre os rumos do agronegócio e das ações ambientais no estado torna-se preocupante, em virtude das discrepâncias de poder entre os grupos envolvidos. Diante 
disso, pode-se questionar: será viável o desenvolvimento autêntico e autônomo dos municípios tocantinenses, envolvendo qualidade ambiental, justiça social e o bem-estar de seus habitantes, de acordo com esses moldes?

\section{Referências}

AB'SÁBER, A. N. O domínio dos cerrados. In: AB'SÁBER, A. N. (Org.). Os domínios de natureza no Brasil: potencialidades paisagísticas. São Paulo: Ateliê Editorial, 2003. p. 115135.

ACSELRAD, H.; MELLO, C. C. A.; BEZERRA, G. N. O que é justiça ambiental. Rio de Janeiro: Garamond, 2009.

ALMEIDA, C. T.; OLIVEIRA JÚNIOR, J. F.; DELGADO, R. C.; CUBO, P.; RAMOS, M. C. Spatiotemporal rainfall and temperature trends throughout the Brazilian Legal Amazon, 1973-201. International Journal of Climatology, v. 37, n. 4, p. 2013-2026, 2016. Disponível em: http://dx.doi.org/10.1002/joc.4831 Acesso em: 6 out. 2016.

BALBINOT, R.; OLIVEIRA, N. K. de; VANZETTO, S. C.; PEDROSO, K.; VALERIO, A. F. O papel da floresta no ciclo hidrológico em bacias hidrográficas. Ambiência, v. 4, n. 1, p. 131-149, 2008. Disponível em:

http://revistas.unicentro.br/index.php/ambiencia/article/view/294 Acesso em: 27 jul. 2017.

CAMPOS FILHO, R. P. Um olhar geopolítico sobre a água no Cerrado: apontamentos para uma preocupação estratégica. In: PELÁ, M.; CASTILHO, D. (Org.). Cerrados: perspectivas e olhares. Goiânia: Vieira, 2010. p. 93-111.

CARVALHO, F. M. V.; DE MARCO JÚNIOR, P.; FERREIRA, L. G. The Cerrado intopieces: habitat fragmentation as a function of landscape use in the savannas of central Brazil. Biological Conservation, v. 142, p. 1392-1403, 2009. Disponível em: http://dx.doi.org/10.1016/j.biocon.2009.01.031 Acesso em: 25 jul. 2017.

CASTILHO, D.; CHAVEIRO, E. F. Por uma análise territorial do Cerrado. In: PELÁ, M.; CASTILHO, D. (Org.). Cerrados: perspectivas e olhares. Goiânia: Vieira, 2010. p. 35-50.

CHAVEIRO, E. F.; BARREIRA, C. C. M. A. Cartografia de um pensamento de Cerrado. In: PELÁ, M.; CASTILHO, D. (Org.). Cerrados: perspectivas e olhares. Goiânia: Vieira, 2010. p. 15-33.

DAHL, A. L. Achievements and gaps in indicators for sustainability. Ecological indicators, v. 17, p. 14-19, 2012. Disponível em: https://doi.org/10.1016/j.ecolind.2011.04.032 Acesso em: 1 ago. 2017.

DIEGUES, A. C. S. Sociobiodiversidade. In: FERRARO JÚNIOR, L. A. (Org.). Encontros e caminhos: formação de educadoras(es) ambientais e coletivos educadores. Brasília: MMA, 2005. p. 303-312. 
ELIAS, D. Reestruturação produtiva da agropecuária e novas regionalizações no Brasil. In: ALVES, V. E. L. (Org.). Modernização e regionalização nos Cerrados do Centro-Norte do Brasil. Rio de Janeiro: Consequência, 2015. p. 25-44.

EMPRESA BRASILEIRA DE PESQUISA AGROPECUÁRIA (EMBRAPA). Avaliação da aptidão agrícola das terras do Matopiba. Brasília, set. 2014. Disponível em: https://www.embrapa.br/web/portal/busca-de-noticias/-/noticia/2038675/avaliacao-daaptidao-agricola-das-terras-do-matopiba Acesso em: 2 jul. 2016.

FEARNSIDE, P. M. Desmatamento na Amazônia: dinâmica, impactos e controle. Acta Amazonica, v. 36, n. 3, p. 395-400, 2006. Disponível em: http://dx.doi.org/10.1590/S004459672006000300018 Acesso em: 21 jul. 2017.

FRANÇOSO, R. D.; BRANDÃO, R.; NOGUEIRA, C. C.; SALMONA, Y. B.; MACHADO, R. B.; COLLI, G. R. Habitat loss and the effectiveness of protected

areas in the Cerrado Biodiversity Hotspot. Natureza \& Conservação, v. 13, p. 35-40, 2015. Disponível em: http://dx.doi.org/10.1016/j.ncon.2015.04.001 Acesso em: 21 jul. 2017.

INSTITUTO BRASILEIRO DO MEIO AMBIENTE E DOS RECURSOS NATURAIS RENOVÁVEIS (IBAMA). Vendas de agrotóxicos e afins no Brasil no período de 2000 a 2014. Brasília: IBAMA, 2016. Disponível em:

http://www.ibama.gov.br/agrotoxicos/relatorios-de-comercializacao-deagrotoxicos\#historicodecomercializacao Acesso em: 28 jul. 2017.

INSTITUTO NACIONAL DE PESQUISAS ESPACIAIS (INPE). Projeto PRODES: monitoramento da floresta amazônica brasileira por satélite: taxas anuais do desmatamento 1988 até 2016. Brasília: INPE/MCTI, 2017. Disponível em:

http://www.obt.inpe.br/prodes/prodes_1988_2016n.htm Acesso em: 8 ago. 2017.

LIMA, D. A. A expansão da fronteira agrícola moderna nos cerrados do Centro-Norte e o avanço dos monocultivos da soja no Tocantins. In: ALVES, V. E. L. (Org.). Modernização e regionalização nos Cerrados do Centro-Norte do Brasil. Rio de Janeiro: Consequência, 2015. p. 325-351.

MAITELLI, G. T.; OLIVEIRA, H. H. C. de. Desmatamentos e variações climáticas na região norte de Mato Grosso: os exemplos dos municípios de Vera e Sinop. In:

MARANDOLA Jr., E.; D’ANTONA, A. de O.; OJIMA, R. (Org.). População, ambiente e desenvolvimento: mudanças climáticas e urbanização no Centro-Oeste. Campinas: Núcleo de Estudos de População NEPO/UNICAMP; Brasília: UNFPA, 2011. p.151-167.

MALHEIROS, R. A influência da sazonalidade na dinâmica da vida no bioma Cerrado. Revista Brasileira de Climatologia, v. 19, p. 113-128, 2016. Disponível em: http://revistas.ufpr.br/revistaabclima/article/view/48876/29384 Acesso em: 21 out. 2016.

MAZZETTO-SILVA, C. E. Ordenamento territorial no Cerrado brasileiro: da fronteira monocultora a modelos baseados na sociobiodiversidade. Desenvolvimento e Meio Ambiente, 
n. 19, p. 89-109, 2009. Disponível em: http://revistas.ufpr.br/made/article/view/16407 Acesso em: 10 out. 2016.

MENDONÇA, L. A. R.; VÁSQUEZ, M. A. N.; FEITOSA, J. V.; OLIVEIRA, J. F. de; FRANCA, R. M. da; VÁSQUEZ, E. M. F.; FRISCHKORN, H. Avaliação da capacidade de infiltração de solos submetidos a diferentes tipos de manejo. Engenharia Sanitária e Ambiental, v. 14, n. 1, p. 89-98, 2009. Disponível em: http://www.scielo.br/pdf/esa/v14n1/v14n1a10 Acesso em: 27 jul. 2017.

MORAIS, R. P. de. As transformações socioeconômicas e ambientais no Cerrado. In: GUIMARÃES, L. D.; SILVA, M. A. D. da; ANACLETO, T. C. (Org.). Natureza viva: Cerrado. Goiânia: UCG, 2006. p. 115-132.

OLIVEIRA, A. U. de. A mundialização do capital e a crise do neoliberalismo: o lugar mundial da agricultura brasileira. Geousp - espaço e tempo (online), v. 19, n. 2, p. 229-245, ago. 2015. Disponível em: http://www.revistas.usp.br/geousp/ article/view/102776 Acesso em: 8 ago. 2016.

PENEREIRO, J. C.; MARTINS, L. L. S.; BERETTA, V. Z. Identificação de variabilidades e tendências interanuais em medidas hidroclimáticas na região hidrográfica do TocantinsAraguaia, Brasil. Revista Brasileira de Climatologia, v. 18, p. 219-241, 2016. Disponível em: http://revistas.ufpr.br/revistaabclima/article/view/38840/28721 Acesso em: 10 out. 2016.

PIGNATI, W.; OLIVEIRA, N. P.; SILVA, A. M. C. da. Vigilância aos agrotóxicos: quantificação do uso e previsão de impactos na saúde-trabalho-ambiente para os municípios brasileiros. Ciência \& Saúde Coletiva, v. 19, n. 12, p. 4669-4678, 2014. Disponível em: http://dx.doi.org/10.1590/1413-812320141912.12762014 Acesso em: 27 jul. 2017.

PIRES, E. G.; FERREIRA, M. E. A influência do uso e cobertura do solo na temperatura de superfície em áreas de Cerrado. In: SIMPÓSIO BRASILEIRO DE CLIMATOLOGIA GEOGRÁFICA, 11, 2014, Curitiba. Anais... Curitiba: ABCLIMA; UFPR, 2014. 12 p. Disponível em: http://www.abclima.ggf.br/publicacoes.php Acesso em: 17 jun. 2015.

PORTO-GONÇALVES, C. W. A globalização da natureza e a natureza da globalização. 5. ed. Rio de Janeiro: Civilização Brasileira, 2013.

RIBEIRO, A. G. As escalas do clima. Boletim de Geografia Teorética, v. 46, n. 23, p. 288294, 1993.

RICHARDS, P. What drives indirect land use change? How Brazil's agriculture sector influences frontier deforestation. Annals of the Association of American Geographers, v. 105, n. 5, p. 1026-1040, 2015. Disponível em: http://www.tandfonline.com/doi/full/10.1080/00045608.2015.1060924 Acesso em: 31 jul. 2017.

ROCHA, G. F.; FERREIRA, L. G.; FERREIRA, N. C.; FERREIRA, M. E. Detecção de desmatamentos no bioma Cerrado entre 2002 e 2009: padrões, tendências e impactos. Revista Brasileira de Cartografia, v. 63, n. 3, p. 341-349, 2011. Disponível em: http://lsie.unb.br/rbc/index.php/rbc/article/viewFile/385/377 Acesso em: 25 jul. 2017. 
ROCHA, M. R. T. da. A rede sociotécnica do babaçu no Bico do Papagaio - TO: dinâmicas da relação sociedade-natureza e estratégias de reprodução social agroextrativista. 2011. $252 \mathrm{f}$. Tese (Doutorado em Desenvolvimento Rural) - Universidade Federal do Rio Grande do Sul, Porto Alegre, 2011.

SALMONA, Y. B. Cerrado com C ou com $S$ ? Modelagem de cenários futuros para o bioma. 2013. 87f. Dissertação (Mestrado em Ciências Florestais) - Universidade de Brasília, Brasília, 2013.

SANTOS, N. B. F. dos. Padrões de distribuições espaciais e temporais de temperatura de superfície no bioma Cerrado: uma análise integrada a partir de dados orbitais de resolução moderada. 2010. 102f. Tese (Doutorado em Ciências Ambientais) - Universidade Federal de Goiás, Goiânia, 2010.

SANTOS, R. F. dos. Planejamento ambiental: teoria e prática. São Paulo: Oficina de Textos, 2004.

SILVA, E. B. da.; ANJOS, A. F. dos. O monitoramento do desmatamento e as ações de conservação do bioma Cerrado na primeira década do século XXI. In: In: PELÁ, M.; CASTILHO, D. (Org.). Cerrados: perspectivas e olhares. Goiânia: Vieira, 2010. p.71-91.

SOARES, W. L.; PORTO, M. F. S. Uso de agrotóxicos e impactos econômicos sobre a saúde. Revista de Saúde Pública, v. 46, n. 2, p. 209-217, 2012. Disponível em: http://www.scielo.br/pdf/rsp/v46n2/3519.pdf Acesso em: 30 out. 2015.

TARIFA, J. R. Alterações climáticas resultantes da ocupação agrícola no Brasil. Revista do Departamento de Geografia, v. 8, p. 15-27, 1994. Disponível em: http://www.revistas.usp.br/rdg/article/view/47323 Acesso em: 30 maio 2016.

TOCANTINS (Estado). Resolução COEMA/TO n. 07, de 9 de agosto de 2005. Dispõe sobre o Sistema Integrado de Controle Ambiental do Estado do Tocantins. Diário Oficial do Estado do Tocantins, Palmas, TO. 9 set. 2005. Disponível em: https://central3.to.gov.br/arquivo/351061/ Acesso em: 25 jul. 2017.

Lucas Barbosa e Souza

Geógrafo pela Universidade Federal de Juiz de Fora (UFJF), Mestre e Doutor em Geografia pela Universidade Estadual Paulista "Júlio de Mesquita Filho" (UNESP), Campus de Rio Claro, Pós-Doutorado em Geografia pela Universidade Federal de Goiás (UFG) com apoio PGPSE/CAPES. É professor da Universidade Federal do Tocantins (UFT), onde atua junto ao Curso de Geografia e aos Programas de PósGraduação em Geografia (Campus de Porto Nacional) e de Ciências do Ambiente (Campus de Palmas).

UFT (Campus de Porto Nacional), Rua 3, Quadra 17, Lote 11, s/n. Setor Jardim dos Ipês, Porto Nacional (TO), CEP 77500-000.

E-mail: lbsgeo@uft.edu.br 


\section{Juliana Ramalho Barros}

Geógrafa pela Universidade de Brasília (UNB), Mestre e Doutora em Geografia pela Universidade Estadual Paulista "Júlio de Mesquita Filho" (UNESP), Campus de Rio Claro. É professora do Instituto de Estudos Socioambientais (IESA) da Universidade Federal de Goiás (UFG), onde atua junto ao Curso de Geografia e ao Programa de Pós-Graduação em Geografia.

IESA/UFG, Av. Esperança, s/n, Campus Samambaia, Goiânia (GO), CEP 74690900.

E-mail: juliana.ufg@superig.com.br

Recebido para publicação em março de 2018 Aprovado para publicação em agosto de 2018 